\title{
Changes in Soluble Sugar Accumulation and Activities of Sucrose-Metabolizing Enzymes during Fruit Ripening of Jackfruit
}

\author{
Ying-zhi Li ${ }^{1}$, Xiao-qiang Duan ${ }^{1}$, Sheng-hui Liu ${ }^{2}$, Ying Li ${ }^{1}$, Xing-hai Zhang ${ }^{3} \&$ Chun-hai $\mathrm{Ye}^{1}$ \\ ${ }^{1}$ Agriculture College, Guangdong Ocean University, Guangdong, China \\ ${ }^{2}$ South Subtropical Crops Research Institute of Chinese Academy of Tropical Agricultural Science, Guangdong, \\ China \\ ${ }^{3}$ Department of Biological Sciences, Florida Atlantic University, Boca Raton, USA \\ Correspondence: Ying-zhi Li, Agriculture College, Guangdong Ocean University, Zhanjiang, Guangdong, China. \\ Tel: 86-0759-238-3247.E-mail: liyz@gdou.edu.cn
}

Chun-hai Ye, Agriculture College, Guangdong Ocean University, Zhanjiang, Guangdong, China. Tel: 86-0759-238-3338. E-mail: gdych@gdou.edu.cn

Received: May 30, 2017

Accepted: June 26, 2017 Online Published: July 15, 2017

doi:10.5539/jas.v9n8p155

URL: https://doi.org/10.5539/jas.v9n8p155

The research is financed by National Natural Science Foundation of China (31101506), Science and Technology Planning Project of Guangdong Province, China (2013B020304004), and Project of Enhancing School with Innovation of Guangdong Ocean University (GDOU2013050217 and GDOU2016050256).

\begin{abstract}
Jackfruit (Artocarpus heterophyllus Lam.) is an important food crop widely grown in the tropical region. However, little is known about sugar metabolism during fruit ripening of jackfruit. Here we examined sugar profiles (sucrose, glucose and fructose) and corresponding enzyme activities (SPS, E.C.2.4.1.14; SuSy, EC 2.4.1.13; IV, EC 3.2.1.26) of four soft type and four firm type varieties of jackfruit during four stages of fruit ripening. We found that during fruit ripening, there was a rapid increase in contents of total soluble sugar and sucrose, whereas increases in glucose and fructose contents were much slower. Ratios of glucose versus fructose varied among different varieties and ripening stages but within the range of 0.9 to 1.2 in the ripe fruits. Five of these varieties exhibited markedly high levels of SuSy activity for sucrose synthesis at early ripening stage, and then decreased towards fully ripe stage. All soft type varieties exhibited a conspicuous peak of AIV activity and had overall higher AIV activities than NIV during ripening. The changing patterns for other enzymes varied among varieties. Our studies support the notion that sucrose was the major sugar species contributing to the fruit sweetness, followed by fructose and glucose. We also demonstrated that AIV and NIV were probably the primary enzymes responsible for sucrose hydrolysis during ripening, while SPS and SuSy were responsible for sucrose synthesis. We propose that during fruit ripening of jackfruit, glucose is released from starch hydrolysis, followed by sucrose hydrolysis leading to increase in both glucose and fructose contents.
\end{abstract}

Keywords: jackfruit (Artocarpus heterophyllus Lam.), fruit ripening, sucrose metabolism, enzyme activity

\section{Introduction}

Jackfruit (Artocarpus heterophyllus Lam.) is a medium-sized evergreen tree belonging to the family Moraceae. It is reported to have originated in the Western Ghats region of India (Purseglove, 1968) and the rainforests of Malaysia (Ruehle, 1967). Due to its easy growth and tolerance to pests, diseases, high temperature and drought, jackfruit has been cultivated for centuries, e.g. 3000 to 6000 years in India (Preedy, Watson, \& Patel, 2011), and is mostly grown in tropical or close to tropical climates, especially throughout south-east Asia where it is mainly consumed as fresh fruit or vegetable (Soepadmo, 1991; Wu et al., 2013). It has been predicted that jackfruit may play an increasingly prominent role in achieving food security in the populous Asia under future challenges from climate change.

Jackfruit has the largest known tree-borne fruit, weighing as much as $50 \mathrm{~kg}$ each (Selvaraj \& Pal, 1989), which generally is grouped into two types of soft flesh and firm (hard) flesh. The fruits are sweet and aromatic when 
ripe, rich in carbohydrates (starch and various sugars), vitamins, dietary fiber and minerals, and can be eaten fresh when ripe or cooked as vegetable. Its large starchy seeds can also be cooked as food. Its fibrous fruit rind can be used as livestock feed.

In spite of its obvious potential as a nutritious and healthy food staple, the popularity of jackfruit as a commercial crop is still lackluster, mainly due to its wide variation in fruit quality (Samaddar, 1985). Fruit ripening is one of the most important processes of fruit quality development. Previous studies have examined the free sugar distribution and compositions of fatty acids (Chowdhury, Raman, \& Mian, 1997), carbohydrates (Rahman, Nahar, Jabbar, \& Mosihuzzaman, 1999), aroma volatiles (Swords, Bobbio, \& Hunter, 1978; Rasmussen, 1983; K. Wong, Lim, \& L. Wong, 1992; Maia, Andrade, \& Zoghbi, 2004), carotenoids and phenolics (Chandrika, Jansz, \& Warnasuriya, 2005; Jayasinghe, Rupasinghe, Hara, \& Fujimoto, 2006; Faria, Rosso, \& Mercadante, 2009) from fruits of different jackfruit varieties, as well as antioxidant capacity and phenol content in jackfruit fruit pulp (Jagtap, Panaskar, \& Bapat, 2010). For example, an early study found little changes in fruit total acidity during ripening (Bhatia, Siddapa, \& Lal, 1955). A more recent study reported significant changes in acidity, color, total soluble solids and total sugars in ripening jackfruit (Ong et al., 2006). The inhibitor of the plant hormone ethylene, 1-methylcyclopropene, was found to significantly delay the ripening process and extend the shelf life for 8-12 days (Mata-Montes, Oca, Osuna-Garcia, \& Hemandez-Estrada, 2007), implicating the role of ethylene in fruit ripening in jackfruit. Study on soft and hard types of jackfruit suggested that while both fruit types shared a similar ripening pattern, the soft type exhibited a greater extent of microscopic and chemical changes, which may contribute to its unique textural features (Rahman, Huq, Mian, \& Chesson, 1995).

Sweetness is a major determinant of edible quality of fruits, and depends largely on the type, composition and amount of sugars in fruit. In jackfruit, sucrose, glucose and fructose constitute the major proportion of free sugars (Chowdhury et al., 1997). It is well known that sucrose synthase (SuSy, EC 2.4.1.13) is a bi-functional enzyme that involves both sucrose synthesis and sucrose hydrolysis to glucose and fructose. Sucrose phosphate synthase (SPS, EC 2.4.1.14) and sucrose synthetic SuSy are generally considered the major players in sucrose synthesis using glucose-phosphate and triose-phosphate released from starch breakdown during fruit ripening. On the other hand, both SuSy and invertases (IV, EC 3.2.1.26) can catalyze sucrose hydrolysis to glucose and fructose.

Although previous studies have examined changes in sugar contents during ripening of jackfruit (Chowdhury et al., 1997; Rahman et al., 1999; Ong et al., 2006), there is no published study that correlates sugar contents with responsible sugar metabolic enzymes during ripening process. In order to better understand the mechanisms underlying sucrose metabolism during jackfruit ripening, we investigated changes in enzyme activities of SPS, SuSy and IV along with sucrose, glucose, fructose and total soluble sugar accumulation during fruit ripening in both soft and firm varieties of jackfruit. Understanding of the biochemical kinetics associated with sugar accumulation during fruit ripening will help select, cultivate and breed better varieties of jackfruit to achieve its potential as a valuable major food and fruit crop for the near future.

\section{Method}

\subsection{Plant Materials}

Eight varieties of jackfruit (Artocarpus heterophyllus Lam.) were obtained from a commercial farm in Zhanjiang, Guangdong province, China, including 4 varieties of soft type (12As, 12Cs, 13Bs and 13Ls) and 4 varieties of firm type (12E, 13D, 13K and 148-4). Mature fruits that produced a dull, hollow sound when tapped were collected from each variety and immediately transported to the laboratory at Guangdong Ocean University. Fruits were then allowed to ripen at ambient temperature $\left( \pm 28^{\circ} \mathrm{C} ; 70-75 \% \mathrm{RH}\right)$.

For sampling, fruits were first grouped into four ripening stages, ripening stage I (mature fruit), ripening stage II (fruit pulp started to soften), ripening stage III (fruit pulp started to form aroma substances) and ripening stage IV (fully ripened), and then were cleaned and cut into two halves. The fruit bulbs from middle portion were deseeded and 10 samples weighing about $1 \mathrm{~g}$ each were collected. Three fruits at each stage were sampled for each variety. The sampled fruit pulps were stored in a freezer $\left(-80^{\circ} \mathrm{C}\right)$ until further analysis.

\subsection{Determination of Sugar Contents}

Soluble sugars were measured according to Li, Liu, Zhu and Yang (2014b). Approximately 3 g pulp randomly mixed from 3 samples of each fruit was extracted three times in $4 \mathrm{ml} \mathrm{80 \%} \mathrm{ethanol} \mathrm{(v:v).} \mathrm{Each} \mathrm{time,} \mathrm{homogenate}$ was centrifuged at $4{ }^{\circ} \mathrm{C}$ and $15,000 \times \mathrm{g}$ for $10 \mathrm{~min}$ and supernatant was collected. Supernatant was then evaporated using a rotary vacuum evaporator (RE-2000A, PUNA, China) at $90{ }^{\circ} \mathrm{C}$ to a final volume of about 1 
$\mathrm{ml}$, and then was added ultrapure water to make the final volume to $30 \mathrm{ml}$. Five milliliters of the solution were filtered through $0.45 \mu \mathrm{m}$ filter membrane and stored in vials for further analysis.

Contents of soluble sugars were analyzed by PerkinElmer Series 200 HPLC Systems equipped with a PE200 refractive index detector and an AT-130 column oven (AUTO SCIENCE, China), using the CARBOSep CHO-820 Calcium column (Transgenomic, USA). Ultrapure water was used as a mobile phase and the flow rate was $0.5 \mathrm{ml} / \mathrm{min}$. Ten microliters of the extracted sample were injected and the temperature of the column was 90 ${ }^{\circ} \mathrm{C}$. Sucrose, glucose and fructose were identified by their retention times and quantified by comparing peak areas of the samples with standards. Data were expressed in $\mathrm{g} / 100 \mathrm{~g}$ of pulp fresh weight.

Total soluble sugar content was measured based on the anthrone method (Irigoyen, Emerich, \& Sanchez-Diaz, 1992). Five milliliters of $0.2 \%$ anthrone were added to $1 \mathrm{ml}$ of the sample solution. The reaction was carried out in boiling water for $10 \mathrm{~min}$, and terminated by incubating the mixture on ice for $5 \mathrm{~min}$. Total soluble content was calculated by creating a standard curve using a standard glucose and was expressed in $\mathrm{g} / 100 \mathrm{~g}$ fresh weight.

\subsection{Enzyme Activity Assay}

Sucrose phosphate synthase (SPS), sucrose synthase (SuSy) and invertase (IV) extractions and assays were conducted by using methods modified from Hubbard, Huber, and Pharr (1989). Frozen sample $(\sim 1 \mathrm{~g})$ was ground in a cold mortar and pestle in $5 \mathrm{ml}$ extraction buffer containing $100 \mathrm{mM}$ Tris- $\mathrm{HCl}(\mathrm{pH} 7.0), 5 \mathrm{mM} \mathrm{MgCl}$, $2 \mathrm{mM}$ EDTA-Na $2,2 \%$ glycol (v/v), $5 \mathrm{mM}$ DTT (dithiothreitol), $0.2 \%$ bovine serum albumin and $2 \%(\mathrm{w} / \mathrm{v}$ ) polyvinylpyrrolidone 40 , and centrifuged at $4{ }^{\circ} \mathrm{C}$ and $10,000 \mathrm{rpm}$ for $30 \mathrm{~min}$. Three $\mathrm{ml}$ of the supernatant were dialysed for $12 \mathrm{hr}$ against 4-hourly changes of $25 \mathrm{mM}$ Tris- $\mathrm{HCl}$ buffer $(\mathrm{pH} 7.0)$ containing $2.5 \mathrm{mM} \mathrm{MgCl}_{2}, 1$ $\mathrm{mM}$ EDTA-Na $2,1 \%$ glycol (v/v) and $2.5 \mathrm{mM}$ DTT. All the enzyme extraction was carried out in triplicate, and assays were performed in triplicate on each extract ( 9 measurements in final per fruit sample).

SuSy sucrose synthesis activity was measured in $1 \mathrm{ml}$ reaction mixture containing $0.4 \mathrm{ml}$ reaction buffer [100 $\mathrm{mM}$ Tris- $\mathrm{HCl}$ ( $\mathrm{pH}$ 7.0), $10 \mathrm{mM}$ fructose, $5 \mathrm{mM}$ magnesium acetate, $5 \mathrm{mM}$ DTT], $0.1 \mathrm{ml} 10 \mathrm{mM}$ UDP-glucose, $0.05 \mathrm{ml}$ freshly desalted extract and $0.45 \mathrm{ml}$ ultrapure water. Measurement for SPS activity in saturated conditions was carried out in $1 \mathrm{ml}$ reaction mixture containing $0.4 \mathrm{ml}$ reaction buffer $[100 \mathrm{mM}$ Tris- $\mathrm{HCl}(\mathrm{pH}$ 7.0), $10 \mathrm{mM}$ fructose-6-P, $5 \mathrm{mM}$ magnesium acetate, $5 \mathrm{mM}$ DTT], $0.1 \mathrm{ml} 10 \mathrm{mM}$ UDP-glucose and $0.05 \mathrm{ml}$ freshly desalted extract. Reaction mixtures were incubated at $30{ }^{\circ} \mathrm{C}$ for $10 \mathrm{~min}$ and then terminated by placing reaction tubes in boiling water for $3 \mathrm{~min}$. The released sucrose was measured based on the anthrone method (Irigoyen et al., 1992). Data were expressed in $\mathrm{mg}$ sucrose produced per hour per gram of fresh pulp.

The SuSy sucrose hydrolytic activity was measured in $1 \mathrm{ml}$ reaction mixture containing $0.4 \mathrm{ml}$ reaction buffer [100 mM Tris- $\mathrm{HCl}$ ( $\mathrm{pH} 7.0$ ), $100 \mathrm{mM}$ sucrose, $10 \mathrm{mM} \mathrm{UDP}$, $0.05 \mathrm{ml}$ freshly desalted extract and $0.55 \mathrm{ml}$ ultrapure water. The neutral IV activity was measured by adding $0.2 \mathrm{ml}$ desalted extract to $0.8 \mathrm{ml}$ reaction buffer made of $80 \mathrm{mM}$ potassium acetate buffer ( $\mathrm{pH} \mathrm{7.0)}$ containing $100 \mathrm{mM}$ sucrose. The acid IV activity was measured by adding $0.2 \mathrm{ml}$ desalted extract to $0.8 \mathrm{ml}$ reaction buffer made of $80 \mathrm{mM}$ potassium acetate buffer (pH 4.5) containing $100 \mathrm{mM}$ sucrose. Reaction mixtures were incubated at $37^{\circ} \mathrm{C}$ for $1 \mathrm{hr}$ and stopped by boiling for $3 \mathrm{~min}$. The amount of reducing sugars produced from sucrose was determined using 3,5-dinitrosalicylic acid method (Luchsinger \& Cornesky, 1962). Data were expressed in $\mu$ g reducing sugar produced per hour per gram of fresh pulp.

\subsection{Statistical Analysis}

Data collected was subjected to one-way analysis of variance (ANOVA) using the SPSS statistical software (version 13.0, USA).

\section{Results}

\subsection{Changes in Sugar Contents during Fruit Ripening of Jackfruit}

During fruit ripening, all eight jackfruit varieties exhibited a trend of increase in contents of total soluble sugar, sucrose, glucose and fructose (Figure 1). Very minute amounts of total soluble sugar and free sugars were detected in unripe fruits (stage I). The contents of glucose and fructose were found to be lowest in the unripe fruit, ranging from $0.1 \%(148-4)$ to $0.3 \%(12 \mathrm{E})$, and $0.004 \%(148-4)$ to $0.18 \%(13 \mathrm{Bs})$, respectively. When fully ripening (stage IV), contents of these two sugars gradually increased, ranging from $1.3 \%$ (13Ls) to $3.3 \%$ (12E) for glucose and from $1.3 \%(13 \mathrm{Ls})$ to $3.3 \%(12 \mathrm{E})$ for fructose (Figure 1). The sucrose and total soluble sugar contents were also lowest in unripe fruit (stage I), ranging from $0.2 \%(13 \mathrm{D})$ to $1.9 \%(12 \mathrm{Cs})$ and $0.7 \%$ (13Ls) to $2.9 \%(12 \mathrm{Cs})$, respectively. However, as the fruits reached full ripening stage IV, the contents of sucrose and total soluble sugar were significantly increased, ranging from $10.6 \%$ (13Ls) to $15.5 \%$ (13D) and from $15.0 \%$ (13Ls) to $25.1 \%(12 \mathrm{E})$, respectively (Figure 1). 

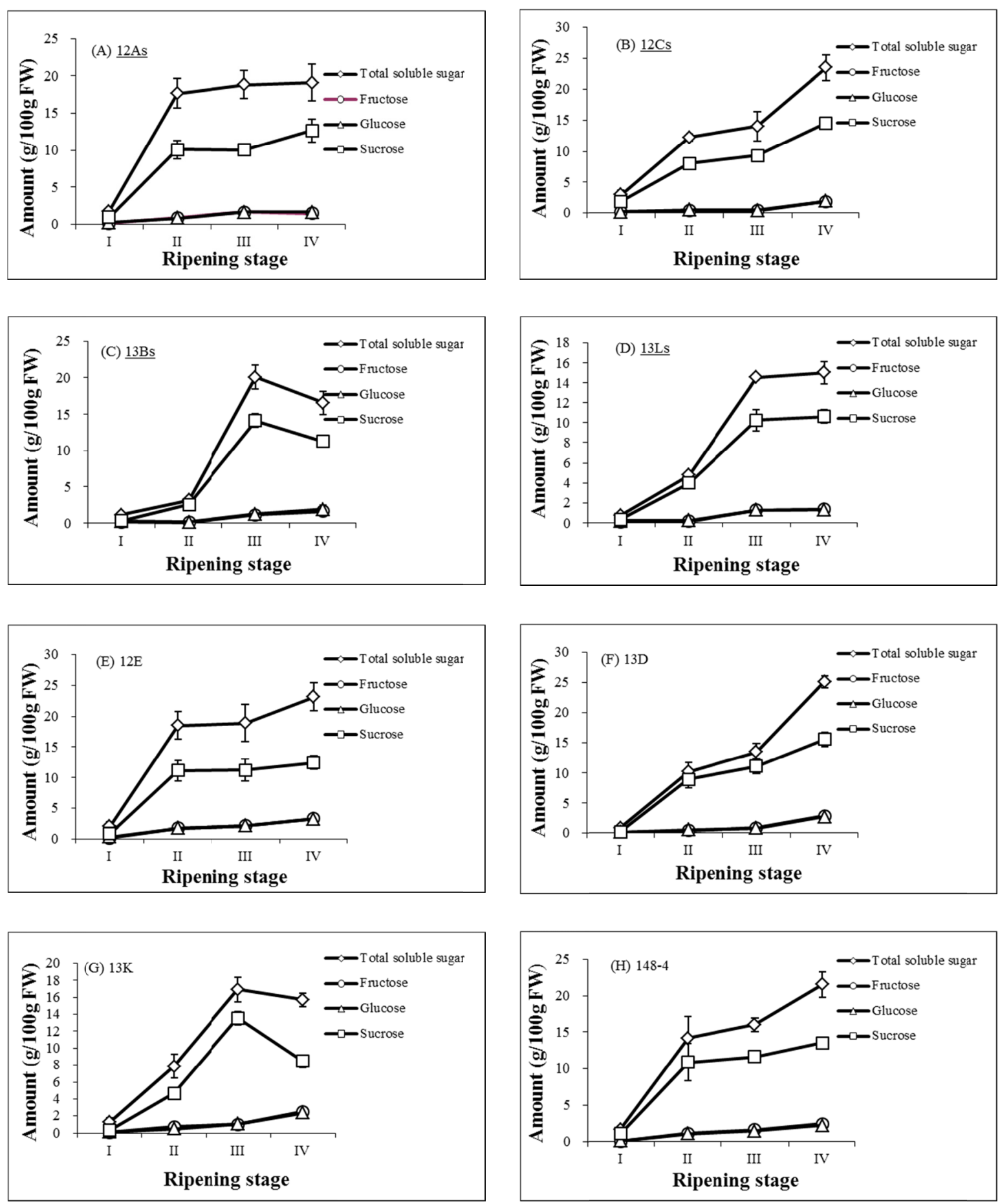

Figure 1. Changes in sugar contents during four ripening stages in 8 jackfruit varieties. Soft types (A-D, underlined): $12 \mathrm{As}, 12 \mathrm{Cs}, 13 \mathrm{Bs}$ and $13 \mathrm{Ls}$. Firm types (E-H): 12E, 13D, 13K, 148-4. Fruit ripening stage I: mature; II: fruit pulp starting to soften; III: fruit pulp starting to form aroma substance; and IV: fully ripened. Data points are mean of three replications with standard error

Changes in the ratio of sucrose content versus content of [glucose + fructose] during fruit ripening (Figure 2A) reflect the equilibrium status of conversion between sucrose and its two monomers. One obvious pattern is that ripening stage I represented the lowest ratio for 7 varieties, suggesting a relatively lower sucrose accumulation. One exception was variety 148-4, which showed the highest ratio at stage I (Figure 2A), largely due to almost absence of fructose in fruit at stage I (Figure 1H). Varieties 12As, 13Bs, 13D and 13Ls all had the peaked ratio at 
stage II, while the ratio for variety $12 \mathrm{Cs}$ increased through stage I to III (Figure $2 \mathrm{~A}$ ). Interestingly, variety $12 \mathrm{E}$ had a somewhat steady ratio throughout four ripening stages (Figure 2A).

For the glucose: fructose ratio, a relatively steady trend was observed across different varieties and ripening stages, within the range of 0.7 to 2.9 (Figure 2B). One exception was the fruits of variety 148-4 at ripening stage I with a value of 28.1 (see note of Figure 2B), as a result of almost non-existence of fructose (Figure 1). However, the glucose:fructose ratio for ripe fruits (stage IV) of all 8 varieties remained from 0.9 to 1.2 , suggesting similar amounts of glucose and fructose in fully ripened fruits.
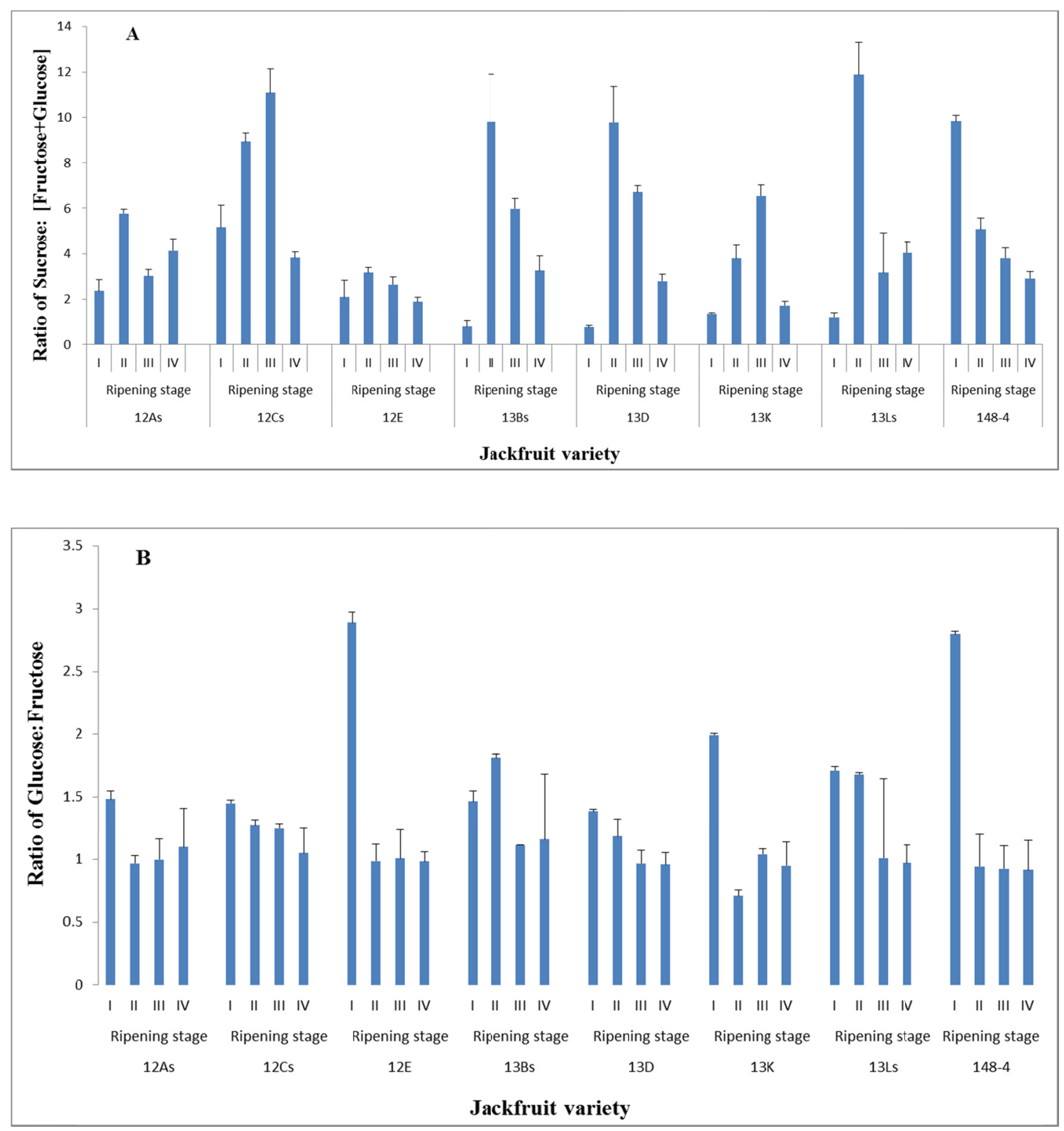

Figure 2. Changes in ratios of sucrose versus [glucose + fructose] contents (A) and glucose versus fructose contents (B) in fruits of 8 jackfruit varieties during 4 ripening stages as described in Figure 1. Note: variety $148-4$, stage I was shown $10 \%$ of the actual ratio of 28.1 . Data points are mean of three replications with standard deviation

\subsection{Changes in Sucrose Synthase (SuSy) Activities during Fruit Ripening}

Two types of SuSy activities were assayed. As shown in Figure 3, most varieties exhibited relatively high levels of SuSy sucrose synthetic activity at ripening stage I, and decreased as the fruit progressed towards the fully 
ripened stage. For example, SuSy synthetic activities in variety 12As decreased from peak at stage I and remained steady through stage IV (Figure 3A). Correspondingly, sucrose contents in this variety showed rapid increase from stage I to stage II, and slightly increased from stage II to stage IV (Figure 1A). Similar patterns can be observed in some other varieties as well (Figure 3B), which corresponds with sucrose content changes (Figure 1). Three varieties, 13Bs, 13Ls and 13K, were somewhat different in that the SuSy sucrose synthetic activity increased at ripening stage IV (Figures 3C, 3D, and 3G) whereas no significant increase in sucrose contents was detected at this stage (Figures $1 \mathrm{C}, 1 \mathrm{D}$ and $1 \mathrm{G}$ ).

For the SuSy sucrose hydrolysis (breakdown) activity, all 8 varieties of jackfruit shared largely a similar pattern during fruit ripening. Overall, this enzyme activity oscillated throughout four ripening stages but overall was consistently low compared to other enzymes (Figure 3). There appeared no obvious correlation between changes in SuSy sucrose hydrolysis activity and changes in contents of sucrose, glucose or fructose (Figure 1). Therefore, we suggest that SuSy sucrose hydrolytic activity may not be primarily responsible for sucrose hydrolysis during fruit ripening of jackfruit, as similarly hypothesized for banana (Nascimento, Cordenunsi, \& Lajolo, 2000).
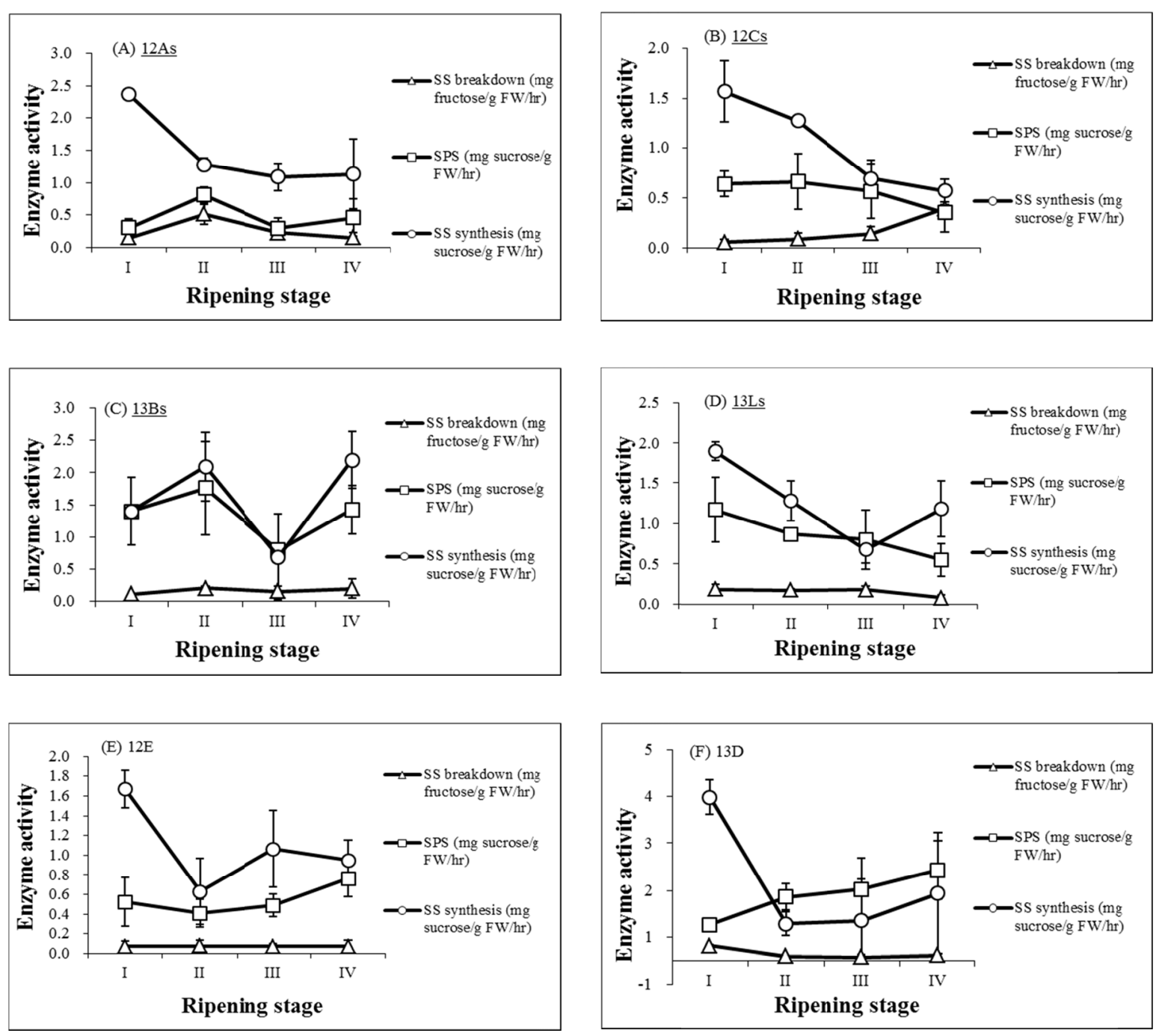

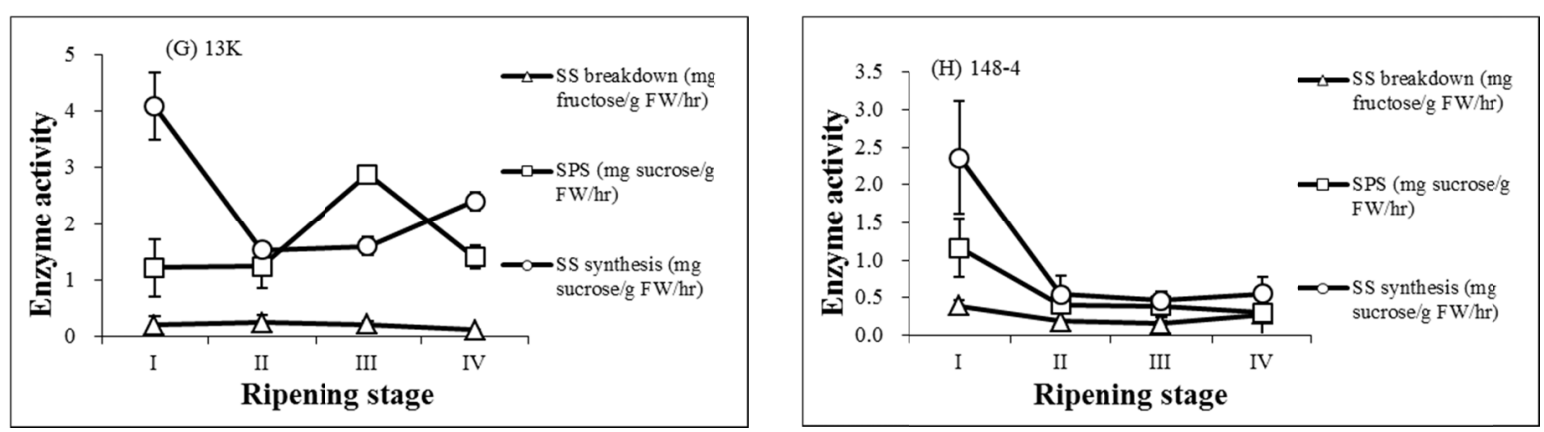

Figure 3. Activities of sucrose synthase (SuSy) and sucrose phosphate synthase (SPS) during fruit ripening of 8 varieties of jackfruit. Both activities for sucrose synthesis and breakdown (hydrolysis) of SuSy were measured.

Soft types (A-D, underlined) and firm types (E-H), and four fruit ripening stages are described in Figure 1

\subsection{Changes in Sucrose Phosphate Synthase (SPS) Activity during Fruit Ripening}

SPS is another major enzyme responsible for sucrose synthesis in fruits. Various patterns of changes were observed among these 8 jackfruit varieties. Varieties 12Cs, 13Ls and 148-4 shared a similar trend where SPS activity steadily decreased from stage I through stage IV (Figures 3B, 3D and 3H). On the other hand, varieties $12 \mathrm{E}, 13 \mathrm{D}$ and $13 \mathrm{~K}$ showed a trend of SPS activity steady increase through stage I to IV (Figures 3E, 3F and 3G), whereas varieties 12As and 13Bs exhibited up and down SPS activities (Figures 3A and 3C). Overall, the SPS activity was much higher than SuSy sucrose hydrolysis activity throughout the ripening stages, thus contributing to sucrose accumulation in fruits.

\subsection{Changes in Invertase Activities during Fruit Ripening}

Although acid invertase (AIV) activity varied from variety to variety during ripening, some interesting aspects were noted (Figure 4). Except for varieties 12E and 13K, all other varieties presented an increase trend of AIV activity throughout the fruit ripening process. Furthermore, all 4 soft type varieties exhibited an obvious peak of AIV activity (Figures 4A-4D), whereas the single peak AIV activity was observed in only 1 out of 4 firm type varieties (Figures 4E-4H). This rapidly increased AIV activity would promote glucose and fructose accumulation in fruits.

Like AIV, the neutral invertase (NIV) activity changed as ripening progressed. Six varieties including all 4 soft type varieties maintained a largely steady NIV activity throughout the 4 ripening stages (Figures 4A-4D, 4G and $4 \mathrm{H}$ ), which is in contrast to single AIV peaks as described above. Overall, NIV activities were lower than AIV during ripening of the soft type jackfruits (Figures 4A-4D). By contrast, the firm type varieties all had higher NIA activities than AIV through ripening stages (Figures 4E-4H). This IV preference points at the possibility that the fruit cellular $\mathrm{pH}$ changes differently for soft and firm jackfruits during ripening. As a result, the different activities of these two types of invertases during fruit ripening may contribute to the distinct textural traits for soft and firm jackfruits.
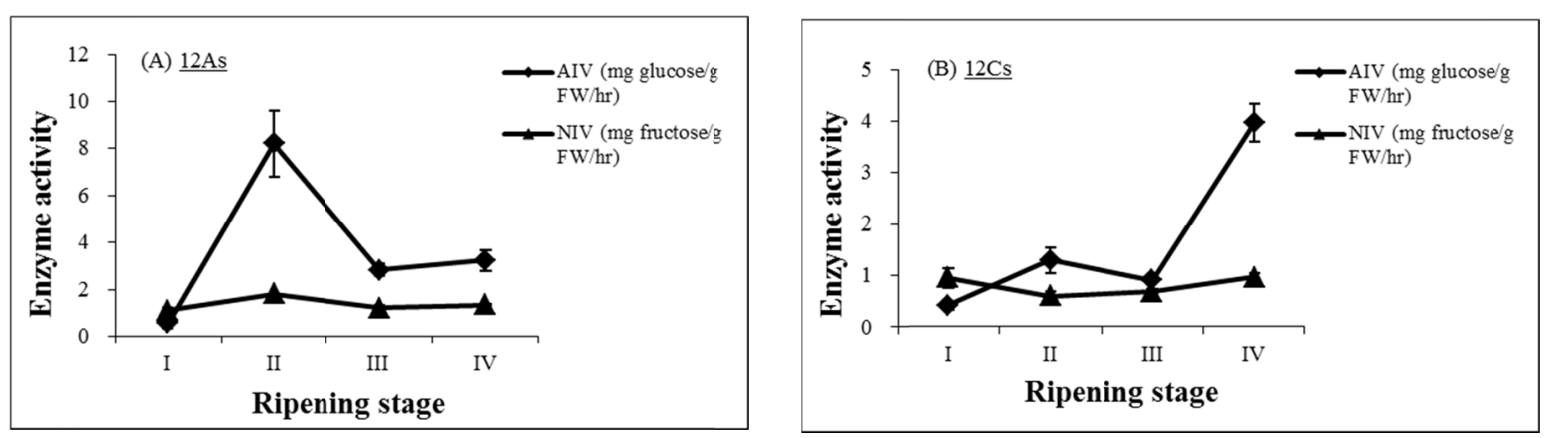

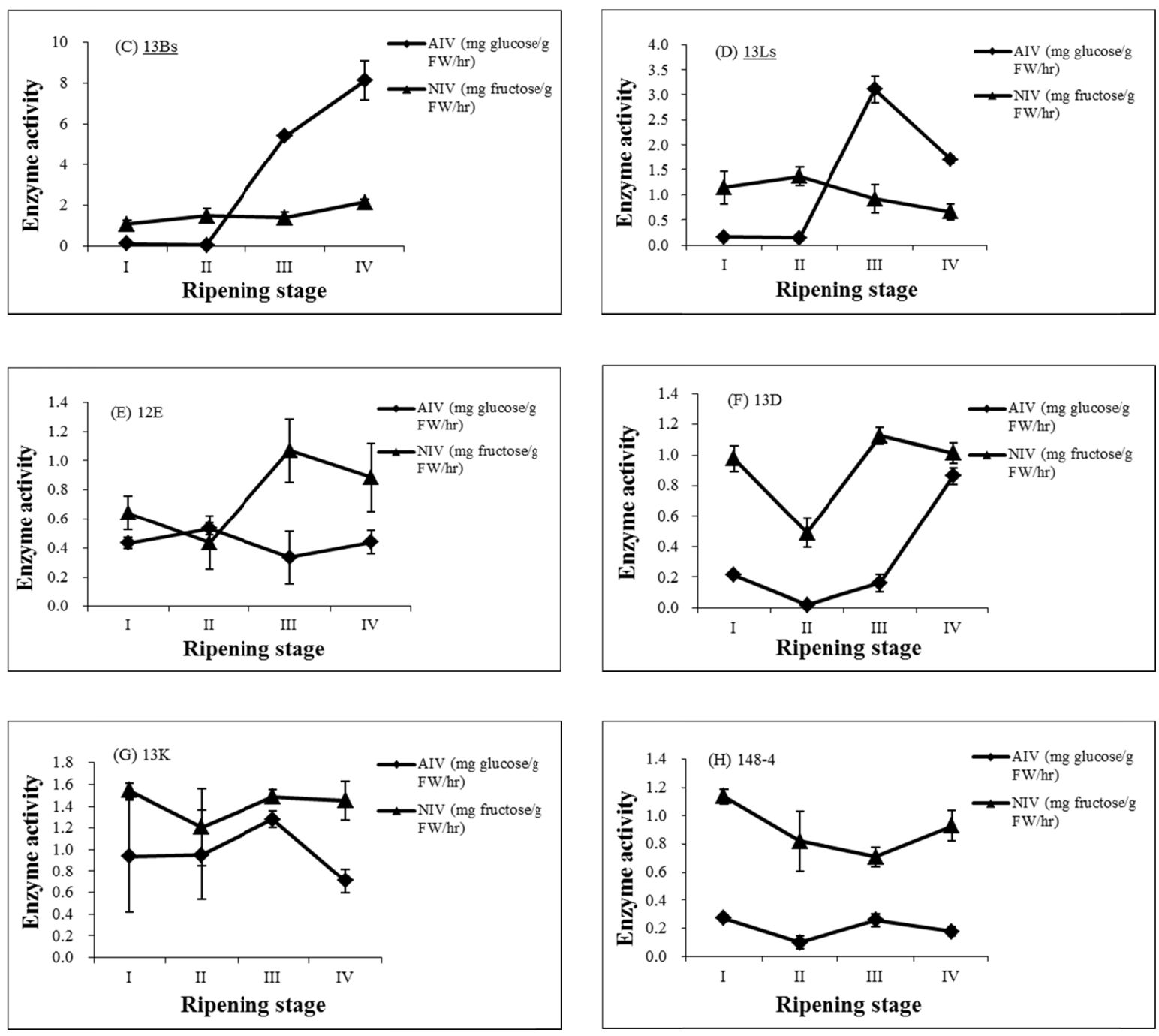

Figure 4. Activities of acid invertase (AIV) and neutral invertase (NIV) during fruit ripening of 8 varieties of jackfruit. Soft types (A-D, underlined) and firm types (E-H), and four fruit ripening stages are described in Figure 1

\section{Discussion}

In this study, we investigated the kinetic changes of sugar accumulation during ripening of eight different jackfruit varieties. Overall, changes in contents of total soluble sugar, sucrose, glucose and fructose were similar among these varieties examined, characterized by rapid increase in sucrose and total soluble sugar contents during fruit ripening. This is largely consistent with previous studies of ripening jackfruit (Selvaraj \& Pal, 1989; Rahman et al., 1999; Ong et al., 2006). Increase in free sugars during fruit ripening can be attributed to starch hydrolysis, a process commonly observed in many fruits including jackfruit (Selvaraj \& Pal, 1989; Rahman et al., 1995), guava (Bashir \& Abu-Goukh, 2003) and banana (Garcia \& Lajalo, 1988).

The average contents of sucrose, fructose and glucose in ripe fruits of our 8 jackfruit varieties were higher than the J3 cultivar reported by Ong et al. (2006), but total soluble sugar in our varieties were lower than the selections of Western Ghats of India (Jagadeesh et al., 2007). Rahman et al. (1999) suggested that soft type varieties had higher total free sugar contents than firm type varieties. However, our study found overall lower total free sugar contents in most of the soft varieties than the firm varieties. This discrepancy may be due to the differences in sugar isolation and sampling procedures, degree of fruit maturity, and plant growth conditions. There seems no clear correlation between sugar content and types (soft or firm) of jackfruits.

It is now well known that sucrose is the major sugar contributing to sweetness of jackfruit, followed by fructose and glucose (Chowdhury et al., 1997; Ong et al., 2006; Rahman et al., 1995, 1999; and this study). Some 
varieties of tomato (Klann, Chetelat, \& Bennett, 1993), watermelon (Yativ, Harary, \& Wolf, 2010) and banana (Fils-Lycaon et al., 2011; Choudhury, Roy, \& Sengupta, 2009) have been characterized as predominantly sucrose- or hexose-accumulating. Our study (Figure 1) clearly shows an abundant accumulation of sucrose in the ripening fruits of all 8 varieties, suggesting that jackfruit is most likely a sucrose accumulator.

The difference between contents of total soluble sugar and free sugar (sucrose, glucose and fructose) among different varieties may be related to the process of cell wall decomposition during fruit ripening, which causes the release of saccharides (Rees, Dixon, Pollock, \& Franks, 1981; Rahman et al., 1995) as well as residual soluble starch stored in vacuole and plastids. Previous studies reported a wide range of glucose vs fructose ratio, from 0.5 to 42, in ripe fruits for both soft and firm type varieties (Rahman et al., 1995; Chowdhury et al., 1997; Rahman et al., 1999; Ong et al., 2006). We found that the glucose:fructose ratio for the 8 jackfruit varieties tested ranged from 0.9 to 1.2 , suggesting a similar content for these two sugars. Therefore, we believe that the glucose:fructose ratio is probably ripening stage- and variety-specific rather than type (soft or firm) specific.

Sugar accumulation during fruit ripening probably results from increased starch hydrolysis and decreased respiration-associated sugar breakdown, as reported in guava (Bashir \& Abu-Goukh, 2003), jackfruit (Li et al., 2014a; Rahman et al., 1995), mangoes (Simäo et al., 2008; Castillo, Kruger, \& Whatley, 1992) and banana (S. Chacon, Viquez, G. Chacon, 1987; Garcia \& Lajalo, 1988). A likely scenario during fruit ripening of jackfruit is that glucose is first accumulated from starch hydrolysis, followed by glucose and fructose accumulation as a result of sucrose hydrolysis. This is supported by the facts that more glucose than fructose was measured at ripening stage $\mathrm{I}$ in all varieties we tested (Figure 2B). When fruits reached the stage of fully ripe, starch hydrolysis finished and sucrose hydrolysis caused the molar ratio of glucose versus fructose to be close to one as observed in our study.

A direct correlation between sucrose accumulation and increased enzyme activity of SPS has been reported for typical climacteric fruits tomato (Yelle, Chetelat, Dorais, De Verna, \& Bennett, 1991; Dali, Michaud, \& Yelle, 1992) and muskmelon (Hubbard, Pharr, \& Huber, 1989), but not for banana (Fils-Lycaon et al., 2011). Our study did not find such a clear correlation for most of the jackfruit varieties tested (Figures 1 and 3). Considering that SPS activity in most of the jackfruit varieties was lower than SuSy sucrose synthetic activity (Figure 3), we propose that SuSy is the major enzyme contributing to sucrose synthesis and accumulation during fruit ripening, whereas SPS may play a minor role, at least for the jackfruit varieties we have tested. However, the precise biochemical mechanism for sucrose accumulation in jackfruits is still unknown.

Among the three enzymes responsible for sucrose hydrolysis, AIV was more active than NIV and NIV was more active than SuSy throughout the four ripening stages (Figures 3 and 4), suggesting AIV probably serving a primary role, followed by NIV, in hydrolyzing sucrose in jackfruit during fruit ripening. One interesting observation was a conspicuous peak AIV activity during fruit ripening of soft varieties, but not so obvious for firm varieties (Figure 4). Since the AIV enzymes in our study were extracted using the gentle conditions without adding salt and thus were most likely a vacuolar form, we speculate that the AIV peak activity observed only in soft type jackfruit (Figure 4) could be the cell wall bounded AIV form, released by cell wall degradation during fruit ripening of soft type jackfruit (Li et al., 2014a; Rahman et al., 1995), which is not likely to occur actively in the firm type jackfruits.

In conclusion, the results of this study support the conclusions that sucrose is the major sugar contributing to sweetness of jackfruit, followed by fructose and glucose. Although the glucose:fructose ratio varies during ripening process, it reaches close to one in ripe fruits. Our study also reveals that among the enzymes examined, AIV is more active than NIV for sucrose hydrolysis, while SuSy probably plays a more important role than SPS in sucrose synthesis and accumulation during fruit ripening. We propose that in early stages of fruit ripening, glucose is released from starch hydrolysis followed by sucrose hydrolysis that contributes to increase in levels of both glucose and fructose. In ripe fruit, while sucrose is still the dominant form of the free sugar, its elevated hydrolysis results in almost equal amount of glucose and fructose.

\section{Acknowledgements}

This research was supported by National Natural Science Foundation of China (31101506), Science and Technology Planning Project of Guangdong Province, China (2013B020304004), and Projects of Enhancing School with Innovation of Guangdong Ocean University (GDOU2013050217 and GDOU2016050256). Y. Z. Li and C. H. Ye conceived and designed the experiments. Y. Z. Li, X. Q. Duan, S. H. Liu and Y. Li performed the experiments. Y. Z. Li, X. H. Zhang and C. H. Ye analyzed the data and wrote the manuscript. All commented on the manuscript. 


\section{References}

Bashir, H. A., \& Abu-Goukh, A. B. A. (2003). Compositional changes during guava fruit ripening. Food Chemistry, 80, 557-563. https://doi.org/10.1016/s0308-8146(02)00345-x

Bhatia, B. S., Siddapa, G. S., \& Lal, G. (1955). Composition and nutritive value of jackfruit. Indian Journal of Agricultural Sciences, 25, 303-306.

Castillo, M., Kruger, N. J., \& Whatley, F. R. (1992). Sucrose metabolism in mango fruit during ripening. Plant Science, 84, 45-51. https://doi.org/10.1016/0168-9452(92)90206-2

Chacon, S. I., Viquez, F., \& Chacon, G. (1987). Physico-chemical profile of banana ripening. Fruits, 42, 95-102.

Chandrika, U. G., Jansz, E. R., \& Warnasuriya, N. D. (2005). Analysis of carotenoids in ripe jackfruit (Artocarpus heterophyllus) kernel and studied their bioconversion in rats. Journal of the Science of Food and Agriculture, 85, 186-190. https://doi.org/10.1002/jsfa.1918

Choudhury, S. R., Roy, S., \& Sengupta, D. N. (2009). A comparative study of cultivar differences in sucrose phosphate synthase gene expression and sucrose formation during banana fruit ripening. Postharvest Biology and Technology, 54, 15-24. https://doi.org/10.1016/j.postharvbio.2009.05.003

Chowdhury, F. A., Raman, M. A., \& Mian, J. (1997). Distribution of free sugars and fatty acids in jackfruit (Artocarpus heterophyllus L.). Food Chemistry, 60, 25-28. https://doi.org/10.1016/s0308-8146(96)00294-4

Dali, N., Michaud, D., \& Yelle, S. (1992). Evidence of the involvement of sucrose phosphate synthase in the pathway of sugar accumulation in sucrose accumulating tomato fruits. Plant Physiology, 99, 434-438. https://doi.org/10.1104/pp.99.2.434

Faria, A. F., Rosso, V. V., \& Mercadante, A. Z. (2009). Carotenoid composition of jackfruit (Artocarpus hterophyllus) determined by HPLC-PDA-MS/MS. Plant Foods for Human Nutrition, 64, 108-115. https://doi.org/10.1007/s11130-009-0111-6

Fils-Lycaon, B., Julianus, P., Chillet, M., Galas, C., Hubert, O., Rinaldo, D., \& Mbéguié, A. (2011). Acid invertase as a serious candidate to control the balance sucrose versus (glucose + fructose) of banana fruit during ripening. Scientia Horticulturae, 129, 197-206. https://doi.org/10.1016/j.scienta.2011.03.029

Garcia, E., \& Lajalo, F. M. (1988). Starch transformation during banana ripening: The amylase and glucosidase behavior. Journal of Food Science, 53, 1181-1186. https://doi.org/10.1111/j.1365-2621.1988.tb13557.x

Hubbard, N. L., Huber, S. C., \& Pharr, D. M. (1989). Sucrose phosphate synthase and acid invertase as determinants of sucrose concentration in developing muskmelon (Cucumis melo L.) fruit. Plant Physiology, 91, 1527-1534. https://doi.org/10.1104/pp.91.4.1527

Hubbard, N. L., Pharr, D. M., \& Huber, S. C. (1990). Role of sucrose phosphate synthase in sucrose biosynthesis in ripening bananas and its relationship to the respiratory climacteric. Plant Physiology, 94, 201-208. https://doi.org/10.1104/pp.94.1.201

Irigoyen, J. J., Emerich, D. W., \& Sanchez-Diaz, M. (1992). Water stress induced changed in concentrations of proline and total soluble sugars in nodulated alfalfa (Medicago sativa) plants. Physiologia Plantarum, 84, 55-60. https://doi.org/10.1034/j.1399-3054.1992.840109.x

Jagadeesh, S. L., Reddy, B. S., Swamy, G. S. K., Gorbal, K., Hegde, L., \& Raghavan, G. S. V. (2007). Chemical composition of jackfruit (Artocarpus heterophyllus Lam.) selections of Western Ghats of India. Food Chemistry, 102, 361-365. https://doi.org/10.1016/j.foodchem.2006.05.027

Jagtap, U. B., Panaskar, S. N., \& Bapat, V. A. (2010). Evaluation of antioxidant capacity and phenol content in jackfruit (Artocarpus heterophyllus Lam.) fruit pulp. Plant Foods for Human Nutrition, 65, 99-104. https://doi.org/10.1007/s11130-010-0155-7

Jayasinghe, L., Rupasinghe, G. K., Hara, N., \& Fujimoto, Y. (2006). Geranylated phenolic constituents from the fruits of Artocarpus noblis. Phytochemistry, 67, 1353-1358. https://doi.org/10.1016/j.phytochem.2006. 04.011

Klann, E. M., Chetelat, R. T., \& Bennett, A. B. (1993). Expression of acid invertase gene controls sugar composition in tomato (Lycopersicon) fruit. Plant Physiology, 103, 863-870. https://doi.org/10.1104/ pp.103.3.863 
Li, Y. Z., Dong, L. L., Wang, Y. B., Li, H. B., Zhang, J. Q., \& Ye, C. H. (2014a). Characterization of sugar metabolism of soft and hard flesh jackfruit during ripening of fruit. Journal of Fruit Science, 31, 85-90. https://doi.org/10.13925/j.cnki.gsxb.2014.01.017

Li, Y. Z., Liu, S. H., Zhu, Z. Y., \& Yang, Y. M. (2014b). Determination of glucose, fructose and sucrose in jackfruit by HPLC. Food science, 35, 84-87.

Luchsinger, W. W., \& Cornesky, R. A. (1962). Reducing power by the dinitrosalicylic acid method. Analytical Biochemistry, 4, 346-347. https://doi.org/10.1016/0003-2697(62)90098-2

Maia, J. G. S., Andrade, E. H. A., \& Zoghbi, M. G. B. (2004). Aroma volatiles from two fruit varieties of jackfruit (Artocarpus heterophyllus Lam.). Food Chemistry, 85, 195-197. https://doi.org/10.1016/s03088146(03)00292-9

Mata-Montes, D., Oca, M., Osuna-Garcia, J. A., \& Hemandez-Estrada, A. (2007). Effect of 1-methylcyclopropene (1-MCP) on the physiology and quality of jack fruit (Artocarpus heterophyllus Lam.). Revista Chapingo Serie Horticultura, 13, 165-170. https://doi.org/10.5154/r.rchsh.2007.02.012

Nascimento, J. R., Cordenunsi, B. R., \& Lajolo, F. M. (2000). Sucrose synthase activity and expression during development and ripening in bananas. Journal of Plant Physiology, 156, 605-611. https://doi.org/10.1016/ s0176-1617(00)80219-9

Ong, B. T., Nazimah, S. A. H., Osman, A., Quek, S. Y., Voon, Y. Y., Hashim, D. M., ... Kong, Y. W. (2006). Chemical and flavour changes in jackfruit (Artocarpus heterophyllus Lam.) cultivar J3 during ripening. Postharvest Biology and Technology, 40, 279-286. https://doi.org/10.1016/j.postharvbio.2006.01.015

Preedy, V. R., Watson, R. R., \& Patel, V. B. (2011). Nuts and Seeds in Health and Disease Prevention. Burlington, MA: Academic Press. https://doi.org/10.1016/c2009-0-01960-6

Purseglove, P. (1968). Dicotyledons, Artocarpus heterophyllus-Jackfruit. Tropical crops (Vol. 2, pp. 384-386). Longman, London.

Rahman, A. K. M. M., Huq, E., Mian, A. J., \& Chesson, A. (1995). Microscopic and chemical changes occurring during the ripening of two forms of jackfruit (Artocarpus heterophyllus L.). Food Chemistry, 52, 405-410. https://doi.org/10.1016/0308-8146(95)93290-8

Rahman, M. A., Nahar, N., Jabbar, M. A., \& Mosihuzzaman, M. (1999). Variation of carbohydrate composition of two forms of fruit from jack tree (Artocarpus heterophyllus L.) with maturity and climatic conditions. Food Chemistry, 65, 91-97. https://doi.org/10.1016/s0308-8146(98)00175-7

Rasmussen, P. (1983). Identification of volatile components of jackfruit by gas chromatography/mass spectrometry by two different columns. Analytical Chemistry, 55, 1331-1335. https://doi.org/10.1021/ ac00259a033

Rees, T. A. P., Dixon, W. L., Pollock, C. J., \& Franks, F. (1981). Low temperature sweetening of higher plants. In J. Friend \& M. J. C. Robert (Eds.), Recent Advances in the Biochemistry of Fruits and Vegetables (pp. 41-60). Academic Press, London, New York.

Ruehle, G. D. (1967). Miscellaneous tropical and subtropical Florida fruits (p. 156a). Agricultural Extension Survey, IFAS, University of Florida, Bull.

Samaddar, H. M. (1985). Jackfruit. In T. K. Bose \& S. K. Mishra (Eds.), Fruits of India: tropical and subtropical (pp. 638-649). Naya Prokash/Culcutta, India.

Selvaraj, Y., \& Pal, D. K. (1989). Biochemical changes during ripening of jackfruit (Artocarpus heterophyllus L.). Journal of Food Science and Technology, 26, 304-307.

Simäo, R. A., Silva, A. P. F. B., Peroni-Okita, F. H. G., Nascimento, J., Louro, R. P., \& Lajolo, F. M. (2008). Mango starch degradation. I. A mcriossopic view of the granule during ripening. Journal of Agricultural and Food Chemistry, 56, 7410-7415. https://doi.org/10.1021/jf800467v

Soepadmo, E. (1991). Artocarpus heterophyllus Lam. In E. W. M. Verheiji, \& R. E. Coronel (Eds.), Plant Resources of South-East Asia (No. 2), Edible Fruits and Nuts (pp. 9-83). Pudoc, Wageningen.

Swords, G., Bobbio, P. A., \& Hunter, G. L. K. (1978). Volatile constituents of jack fruit (Artocarpus heterophyllus). Journal of Food Science, 43, 639-640. https://doi.org/10.1111/j.1365-2621.1978.tb02375.x 
Wong, K. C., Lim, C. L., \& Wong, L. L. (1992). Volatile flavour constituents of Chempedak (Artocarpus polyphema Pers.) fruit and Jackfruit (Artocarpus heterophyllus Lam.) from Malaysia. Flavour and Fragrance Journal, 9, 319-324. https://doi.org/10.1002/ffj.2730070604

Wu, G., Chen, H., Sang, L., Xu, F., Liu, A., \& Tan, L. (2013). Status of jackfruit industry in China and development contermeasures. Chinese Journal of Tropical Agriculuture, 33, 91-97.

Yativ, M., Harary, I., \& Wolf, S. (2010). Sucrose accumulation in watermelon fruits: genetic variation and biochemical analysis. Journal of Plant Physiology, 167, 589-596. https://doi.org/10.1016/j.jplph.2009. 11.009

Yelle, S., Chetelat, R. T., Dorais, M., De Verna, J. W., \& Bennett, A. (1991). Sink metabolism in tomato fruit. IV. Genetic and biochemical analysis of sucrose accumulation. Plant Physiology, 95, 1026-1035. https://doi.org/10.1104/pp.95.4.1026

\section{Appendix}

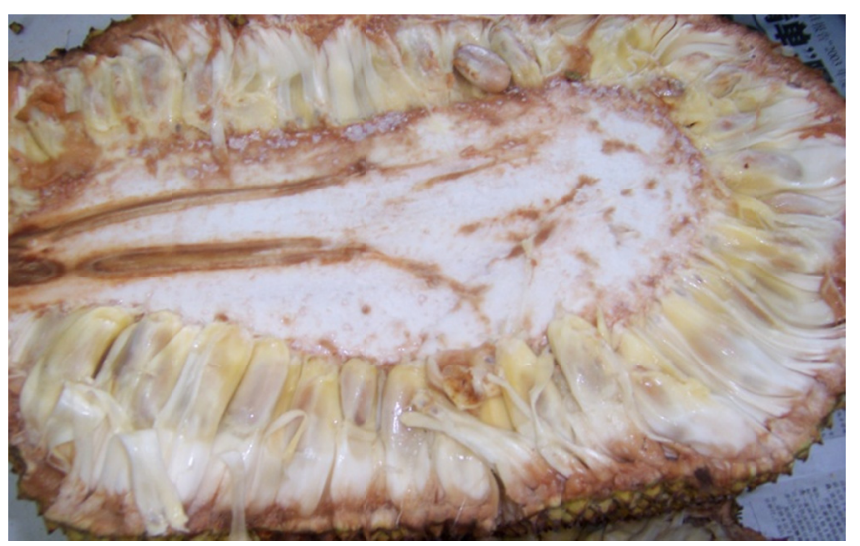

Appendix 1. A longitudinal section of fruit of the soft type jackfruit (variety 12Cs), showing the soft and pulpy flesh

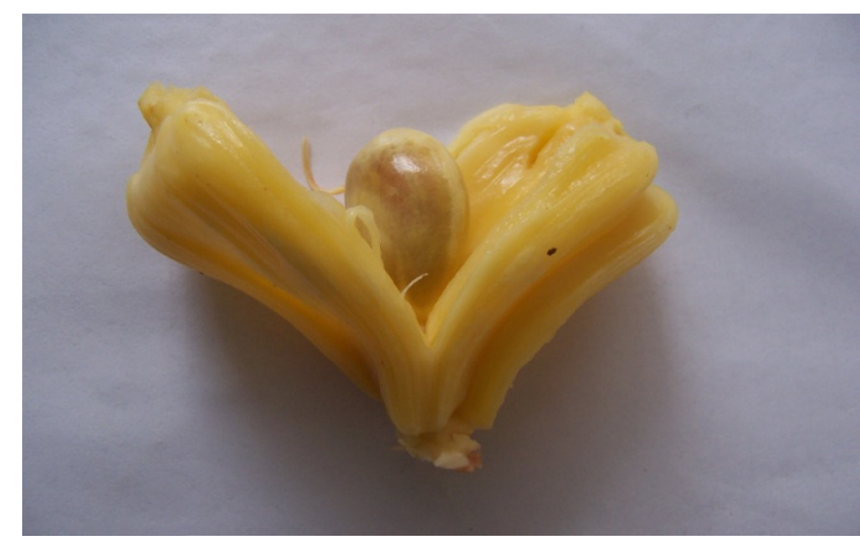

Appendix 2. A single pulp of hard type Jackfruit (variety 12E), showing the firm flesh

\section{Copyrights}

Copyright for this article is retained by the author(s), with first publication rights granted to the journal.

This is an open-access article distributed under the terms and conditions of the Creative Commons Attribution license (http://creativecommons.org/licenses/by/4.0/). 